\title{
PRELIMINARY SCREENING OF PHYTOCHEMICAL CONSTITUENTS, ANTIOXIDANT, AND ANTI-BACTERIAL ACTIVITIES IN THE METHANOLIC LEAF EXTRACT OF MELIOSMA SIMPLICIFOLIA (L.)
}

\author{
PAVITHRA S*, SEKAR T \\ Department of Botany, Bharathiar University, Coimbatore, Tamil Nadu, India. Email: pavithrasampath1993@gmail.com \\ Received: 15 January 2021, Revised and Accepted: 22 February 2021
}

\section{ABSTRACT}

Objective: In the present study is investigated of phytochemicals and antioxidant activities of the leaf extracts from Meliosma simplicifolia (L.).

Methods: The seaweed sample was subjected to extraction with solvents of different polarities (hot water, methanol, acetone, chloroform, and petroleum ether) and screened for phytochemicals according to standard methods. The ability of the plant extract to act as hydrogen/electrons donor or scavenger of radicals was determined by in vitro antioxidant assays using 2,2-diphenyl-2-picryl-hydrazyl free radical (DPPH) scavenging, reducing power assay, and superoxide radical (02•) scavenging activity. The ICPMS and GC-MS analysis of the methanol leaf extract of M. simplicifolia was revealed the presence of antibacterial.

Results: Phytochemical analysis revealed the presence of Preliminary metabolites Quantitative studies of estimated phenol, flavonoid and tannin, as for the methanol extract of stem showed the highest content of phenolic compounds ( $40.71 \pm 0.94 \mathrm{GAE} \mathrm{mg} / 100)$. Antioxidant activities were concluded the estimation M. simplicifolia leaf for as followed the studies. In leaf the highest DPPH scavenging activity (132.3 $\mu \mathrm{g} / \mathrm{ml})$, ICP-MS analysis of the leaf extract showed the presence minerals such as $\mathrm{Mg}, \mathrm{Fe}, \mathrm{Cu}, \mathrm{Na}$, and $\mathrm{Zn}$ in excess. The leaf extract of the plant was also tested for its antibacterial activity and results confirmed that it has potential activity.

Conclusion: The preliminary studies in the methanol extract of the leaf of $M$. simplicifolia are suggestive of the antibacterial potentials of the methanol extract of leaves of $M$. simplicifolia.

Keywords: Meliosma simplicifolia, Antioxidant, ICPMS, GC-MS, Antibacterial.

(c) 2021 The Authors. Published by Innovare Academic Sciences Pvt Ltd. This is an open access article under the CC BY license (http://creativecommons.org/ licenses/by/4.0/) DOI: http://dx.doi.org/10.22159/ajpcr.2021v14i4.40787. Journal homepage: https://innovareacademics.in/journals/index.php/ajpcr

\section{INTRODUCTION}

Herbal medicine is a prescription as yet another foundation of around $75-80 \%$ of the total population, for essential medicinal services. In India, over $70 \%$ of aggregate population utilizes home developed medications for the treatment of illnesses. However, oxygen-center free radicals and other reactive oxygen species (ROS) which are produced in vivo continuously, results in cell death and tissues damage. Scientific evidence has suggested that under oxidative stress conditions, oxygen radicals such as superoxide anions (O2-), hydroxyl radical $(\mathrm{OH})$, and peroxyl radicals $\left(\mathrm{H}_{2} \mathrm{O}_{2}\right)$ are produced in a biological system [1]. When added to foods, antioxidants minimize rancidity, retard the formation of toxic oxidation products, maintain nutritional quality, and increase shelf life [2]. Natural antioxidants are in high demand for application as nutraceuticals, biopharmaceuticals, as well as a food additive because of consumer preference. Some phytochemicals are known to exhibit medicinal and physiological activities which are phenols, tannins, flavonoids, phytosterols, etc. The various prominent bioactive compounds of plants are alkaloids, flavonoids, tannins, and phenolic compounds. Medicinal herb is estimated to be a biochemical laboratory as it contains an abundance of chemical compounds such as alkaloids, glycosides, saponins, resins, oleoresins, lactones, and essential oils [3]. Plant phenols products of the phenylpropanoid pathway Influential antioxidants might limit oxidative destruction to biomolecules such as DNA, lipids, and proteins which play a role in chronic diseases as cancer and cardiovascular [4]. Free radicals produced from absorption or biodegradable resources interact continuously in natural systems and their unconstrained generation associates with the molecular level of the cause by so many diseases [5]. Antioxidants are such essences in life which possess free radicals continue reaction of smashing their properties. At present, there is an improvement of concern in the remedial potential of highly contain medicinal plants as antioxidants and decrease the oxidative stress. It has caused tissue damage of living being [6]. Based on the numerous naturally appear antioxidants such as carotenoids, Vitamin E, Vitamin D, ascorbic acid, and phenolic compounds, those are much effective of reduction [7].

\section{METHODS}

Sodium phosphate, ammonium molybdate, potassium ferricyanide, ferric chloride, 2,2-diphenyl-1-picrylhydrazyl (DPPH), potassium, persulfate, polyvinyl polypyrrolidine (PVPP), sodium nitrite, trichloroacetic acid, ethylenediaminetetraacetic acid (EDTA), aluminum chloride, ferrous sulfate, gallic acid, rutin, quercetin, safranin, and fast green were purchased from Sigma-Aldrich. Solvents used are purchased from HiMedia and all reagents were used without further purification.

\section{Collection of plant material}

Meliosma simplicifolia plant parts were collected from Nilgiris, Western Ghats region of Tamil Nadu, India. The plant material was identified as M. simplicifolia and authenticated by Botanical Survey of India, Southern circle, Coimbatore, and the voucher specimen has been deposited in Bharathiar University, Coimbatore (NO.BSI/SRC/5/23/2018/Tech/2910). The freshly collected plant materials were cleaned to remove dust and impurities using distilled water. Plant materials were washed with distilled water and dried at room temperature. The dried leaf was manually ground to a fine powder and the samples were used for further studies.

\section{Plant extracts preparation}

The powdered plant material was extracted in Soxhlet extractor successively with petroleum ether, chloroform, acetone, methanol, and hot water. Each time before extracting with the next solvent, the thimble 
was dried in hot air oven below $40^{\circ} \mathrm{C}$. Rotary vacuum evaporator was used to concentrate different solvent extracts and then air dried. The dried extract obtained with each solvent was weighed. The percentage yield of air dried weight of plant material was expressed in terms. The anti-inflammatory, antispasmodic, anti-analgesic can be attributed to their excessive steroids, tannin, terpenoids, and saponins. Phytochemicals are responsible for the medicinal pastime of plant life, the different extracts obtained were subjected to preliminary phytochemical screening following standard methods [8-10].

\section{Phytochemical analysis}

Dragendorff's test

To $2 \mathrm{mg}$ of the extracts, $5 \mathrm{ml}$ of distilled water turned into brought; $2 \mathrm{M}$ hydrochloric acid became introduced until an acid reaction takes place. To this, $1 \mathrm{ml}$ of Dragendorff's reagent turned into brought. Formation of orange or orange purple precipitate suggests the presence of alkaloids.

Mayer's test

To some drops of Mayer's reagent, $2 \mathrm{mg}$ of extracts were delivered. Development of white or decreased yellow precipitate determines the appearance of alkaloids.

\section{Test for carbohydrates}

Molisch's test

Few drops of Molisch's reagent was added to $2 \mathrm{ml}$ of the extract and mixed well. $2 \mathrm{ml}$ of concentrated sulfuric acid was added to this solution. Formation of the red-violet ring at the junction of the solution indicates the presence of carbohydrates.

\section{Fehling's test}

$2 \mathrm{mg}$ of extracts had been shaken with $10 \mathrm{ml}$ of water, filtered and the filtrate became focused. To this, $1 \mathrm{ml}$ combination of the same elements of Fehling's answer, A and B were delivered and boiled for a short time. Formation of red or brick red colored precipitate suggests the presence of decreasing sugar.

\section{Test for proteins}

To $1 \mathrm{ml}$ of the extract, few drops of Biuret reagent were added. The formation of the blue color indicates the presence of protein.

\section{Test for amino acids}

Amino acids inside the samples were decided as per the manner of the citrate buffer was prepared by mixing $20.5 \mathrm{~mL}$ of solution A and 29.5 mL of solution.

\section{Test for flavonoids}

Shinoda's test

$2 \mathrm{mg}$ of extracts have been dissolved in $5 \mathrm{ml}$ of ethanol and to this ten drops of dilute hydrochloric acid followed by a small piece of magnesium had been added. Formation of pink, reddish, or brown color shows the presence of flavonoids.

\section{Tannins}

\section{Potassium hydroxide test}

In $10 \mathrm{ml}$ of freshly prepared $10 \%$ potassium hydroxide $(\mathrm{KOH})$ takes in a beaker, $0.5 \mathrm{~g}$ of extract modified into delivered and shaken to dissolve. A dirty precipitate indicated the presence of tannin.

\section{Test for phenolic compounds}

\section{Ferric chloride test}

A little extract was dissolved in $2 \mathrm{ml}$ of distilled water. This was followed by addition of few drops of $10 \%$ ferric chloride. Formation of blue/ green color indicates the presence of phenols.

\section{Test for Saponins}

Foam test

In a take, a look at tube containing approximately $5 \mathrm{ml}$ of extracts, a drop of sodium bicarbonate answer turned into introduced. The check tube becomes shaken vigorously and left for $3 \mathrm{~min}$. Formation of honeycomb-like froth suggests the presence of saponins.

\section{Test for anthraquinone}

$1 \mathrm{ml}$ of the extract was macerated with ether, and after filtration, aqueous ammonia was added. The formations of coloring the layer after shaking red pink, and violet indicate the presence of anthraquinones.

\section{Quantification of total phenolic and tannin}

The overall phenolics approach each tannin and non-tannin phenolics. The amount of tannins turned into calculated by way of subtracting the non-tanninphenolics from overall phenolics. For the determination of non-tannin phenolics (Makkar, 2003), $500 \mu \mathrm{l}$ of each plant extracts had been incubated with $100 \mathrm{mg}$ of polyvinyl polypyrrolidone (PVPP), and $500 \mu \mathrm{l}$ of distilled water taken in a $2 \mathrm{ml}$ Eppendorf tube for $4 \mathrm{~h}$ at ${ }^{\circ} \mathrm{C}$. After incubation the Eppendorf tubes had been centrifuged at $4000 \mathrm{rpm}$ for $10 \mathrm{~min}$ at ${ }^{\circ} \mathrm{C}$. The supernatant consists of simplest the non-tannin phenolics since the tannins would have been deposited in conjunction with PVPP. The supernatant changed into accumulated and the nontannin phenolics were measured with the aid of the equal method described for the quantification of total phenolics. The analyses of total phenolics and free phenolics have been additionally performed in triplicates and the results had been expressed in tannic acid equivalent (TAE). From those effects, the tannin content of the plant samples has been measured as follows,

Tannins $=$ Total phenolics-Non-tannin phenolics

\section{Quantification of total flavonoid}

The flavonoid content of the considerable number of concentrates was evaluated as it goes about as a noteworthy antioxidant in plants diminished oxidative anxiety. Assessed according to portrayed by Zhishen et al. [11]. Initially, $150 \mu \mathrm{l}$ of all the plant extracts were taken in different test tubes. To each extracts $2 \mathrm{ml}$ of distilled water was added. Then, $150 \mu \mathrm{l}$ of $\mathrm{NaNO}_{2}$ was added to all the test tubes followed by incubation at room temperature for $6 \mathrm{~min}$. After incubation, $150 \mu \mathrm{l}$ of $\mathrm{AlCl}_{3}(10 \%)$ was added to all the test tubes. The test tubes were incubated for $6 \mathrm{~min}$ at room temperature. Then, $2 \mathrm{ml}$ of $\mathrm{NaOH}$ was added to all the test tubes which were made up to $5 \mathrm{ml}$ using distilled water. The contents in all the test tubes were vortexes well and they were allowed to stand for $15 \mathrm{~min}$ at room temperature. The pink color developed due to the appearance of flavonoids was read spectrophotometrically at $510 \mathrm{~nm}$. The amount of flavonoids was calculated as rutin equivalents.

\section{In vitro antioxidant studies}

DPPH radical scavenging activity

The stable radical DPPH was used to measure the free radical scavenging activity by the method of [12]. Samples at various concentrations $(20,40,60,80 \mathrm{lg} / \mathrm{mL}$ of extracts with respective organic solvents) were taken and the volume was adjusted to $100 \mathrm{lL}$ with methanol. About $5 \mathrm{~mL}$ of a $0.1 \mathrm{mM}$ methanol solution of DPPH was added to the aliquots of different extracts of plant sample and standards (BHT and Quercetin). $100 \mathrm{lL}$ of methanol in $5 \mathrm{~mL}$ of DPPH solution was used as a negative control. All the reaction mixtures were incubated for $20 \mathrm{~min}$ at $27^{\circ} \mathrm{C}$. Inhibition of DPPH radical by the plant samples was measured at $517 \mathrm{~nm}$ against the blank (methanol).

\section{Heavy metal analysis}

Instrument: Perkin Elmer ICP-MS, Nexion 350× inductively coupled plasma mass spectrometer was used for the determination of the minerals [13].

\section{Sample preparation}

$0.3 \mathrm{~g}$ of leaf and stem powder were weighed into the tri-acid digestion tube and then added with (9:2:1) of concentrated $\mathrm{HNO}_{3}, \mathrm{H}_{2} \mathrm{SO}_{4}$, and perchloric acid. Samples were pre-digested for 15 min. Microwave absorption of the samples was performed utilizing the Mars 6 Microwave digestion method. After cooling, the whole digest were shifted into a $50 \mathrm{ml}$ volumetric flask and reduced to $50 \mathrm{ml}$ with double 
deionized water. Reagent blanks were prepared similarly for all sample solutions.

\section{Reagents}

For sample digestion trace metals-grade concentrated $\mathrm{HNO}_{3}(69-70 \%$, Fisher Scientific) was used. Double deionized water (Milli-Q Millipore $18,2 \mathrm{M} \mathrm{cm}^{-1}$ resistivity) was used for all dilutions. The element standard stock solutions (Sodium [Na], Magnesium [Mg], Aluminum [Al], Chromium [Cr], Manganese [Mn], Zinc [Zn], Copper [Cu], Iron [Fe], Nickel [Ni], Potassium [K], Phosphorus [P], Lead [Pb], and Selenium [Se]) in $1000 \mathrm{mg} \mathrm{L-1}$ used for calibration were supplied by Merck.

\section{ANTIBACTERIAL ACTIVITY}

The antibacterial activity of the leaf extracts was determined using agar well diffusion method with slight modification [14]. The bacteria were cultured in nutrient broth at room temperature and kept in orbital shaking incubator (Remi, India) at $200 \mathrm{rpm}$ for 2-3 days. The Muller hint on agar plates (bacteria culture) was prepared and microbial strains were swabbed. After $5 \mathrm{~min}$, the well ( $5 \mathrm{~mm}$ size) was made using gel puncher and different concentrations $(25 \mu \mathrm{g}, 50 \mu \mathrm{g}, 75 \mu \mathrm{g}$ and $100 \mu \mathrm{g} / \mathrm{ml}$ ) of the sample were added in the well. The positive control $(10 \mu \mathrm{g} / \mathrm{ml})$ (tetracycline) was prepared and poured into wells. The plants were incubated at $37^{\circ} \mathrm{C}$ for $24 \mathrm{~h}$ (bacteria). After incubation, the antibacterial activity was assessed. Each screening test was performed with three replicates and $t$ the mean values are recorded.

\section{Statistical analysis}

The results are expressed as the mean \pm S.E.M. One-way ANOVA followed by Dunnett's multiple comparison tests. Data were computed for statistical analysis using GraphPad Prism version 5.00 for Windows, GraphPad Software, San Diego California USA, and compared with the vehicle control group. $P$ values $(\mathrm{p}<0.05)$ were considered statistically significant.

\section{RESULTS}

\section{Phytochemical screening}

Phytochemical analysis of studied plant extract suggests the presence of, carbohydrates, protein and amino acid, flavonoids, and saponins methanol extracts showed good result compared to acetone and chloroform extracts. Moreover, methanol extracts relatively slight alkaloid, tannin, and anthraquinone of absence (Table 1).

\section{Qualitative and quantitative phytochemical analysis} Quantification of total phenolic, tannins, and flavonoid

In the Soxhlet method for extraction, the bound phenol compounds from plant materials can be released using heat treatment [15]. Estimation of M. simplicifolia leaf and revealed the highest phenolic content in methanol extract $(40.71 \pm 0.94 \mathrm{GAE} / 100 \mathrm{~g})$. From the above results, the tannin content of the sample was calculated as follow: Tannin (\%) = Total phenolics (\%) - Non-tannin phenolics (\%) methanolic extract of leaf and stem $(7.82 \pm 3.23 \mathrm{GAE} / 100 \mathrm{~g})$. Estimation of the M. simplicifolia leaf found to be in maximum amount of flavonoid content in methanol extract $(20.61 \pm 0.28 \mathrm{RU} / 100 \mathrm{~g})$ (Table 2).

\section{In vitro antioxidant assays}

DPPH radical scavenging activity

The free radical-scavenging activities in stem and leaf of the plants M. simplicifolia samples along with standards Vitamin C was determined by the DPPH radical scavenging assay. The reduction in absorbance of the DPPH radical caused by antioxidant was because of the rummaging of the radical by hydrogen ability. The color change from purple to yellow after reduction can be quantified decrease in absorbance at wavelength $517 \mathrm{~nm}$. A lower value of $\mathrm{IC}_{50}$ (inhibitory concentration at $50 \%$ ) indicates a higher antioxidant activity. In leaf, petroleum ether and chloroform extracts show the higher inhibitory $\mathrm{IC}_{50}$ value was $(132.1 \mu \mathrm{g} / \mathrm{ml})$, whereas acetone $(64.69 \mu \mathrm{g} / \mathrm{ml})$ and methanol $(11.23 \mu \mathrm{g} / \mathrm{ml})$ show the minimum inhibitory concentration activity. It has been generally used to test the capacity of mixes as free-radical scavengers or hydrogen contributors and to assess the ant oxidative action of plant concentrates and nourishments [16] (Fig. 1).

\section{Minerals analysis of $M$. simplicifolia}

Inductively Coupled Plasma Mass Spectroscopy (ICPMS) result

In the investigation the physiochemical parameters of the sample were analyzed the determination of essential elements and heavy metals were studied using ICPMS equipment. The results shows the stem sample of M. simplicifolia contains macro element such as magnesium, potassium, calcium, phosphorus, iron, manganese, zinc, copper, molybdenum, and selenium and some heavy metals such as nickel and chromium were also present. The element found in this plant are included in the nine elements that are common in living beings and in humans constitute around $4 \%$ of the body weight [17]. Minerals are part of human organ systems, proteins, enzymes, hormones, etc., they regulate the metabolism and cause disease if not found in adequate amounts or are absent (Table 3).

GC-MS chromatogram of $M$. simplicifolia methanol leaf extract The GC-MS study of the methanolic extract of the leaf M. simpliciflia had shown the presence of many photochemical which might contribute

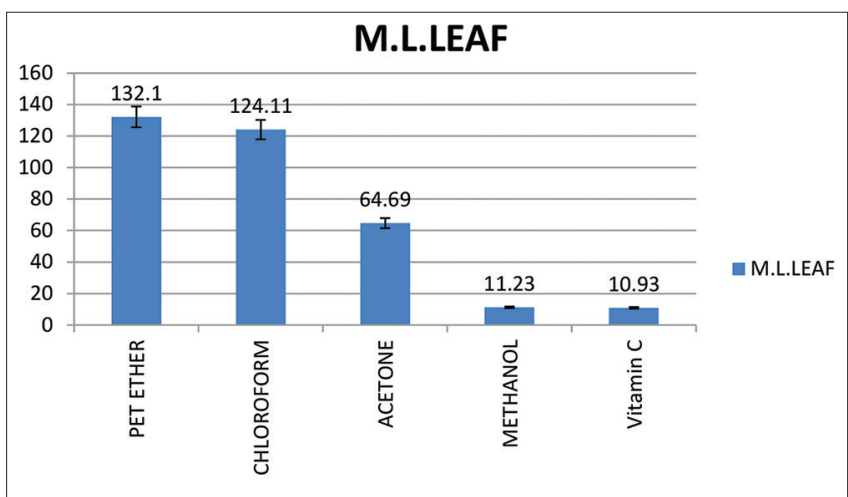

Fig. 1: DPPH radical scavenging activity of Meliosma simplicifolia leaf, values are mean of three replicate determinations $(n=3) \pm$ standard deviation Bars having different letters are significantly different $(\mathrm{p}<0.05)$

Table 1: Phytochemical screening of Meliosma simplicifolia leaf extracts

\begin{tabular}{|c|c|c|c|c|c|c|}
\hline S. No. & Phytochemical test & Pet ether & Chloroform & Acetone & Methanol & Water \\
\hline 1 & Alkaloid & - & - & - & - & - \\
\hline 2 & Carbohydrates & + & + & + & + & + \\
\hline 3 & Protein and amino acid & ++ & ++ & + & ++ & + \\
\hline 4 & Flavonoid & ++ & + & + & ++ & ++ \\
\hline 5 & Tannin & - & - & - & - & - \\
\hline 6. & Phenolic compound & ++ & + & ++ & ++ & ++ \\
\hline 7 & Saponin test & + & + & + & + & + \\
\hline
\end{tabular}


Table 2: Total phenolic, flavonoid and tannin contents of Meliosma simplicifolia

\begin{tabular}{|c|c|c|c|c|c|}
\hline \multirow[t]{2}{*}{ S. No. } & \multirow[t]{2}{*}{ Plant material } & \multirow[t]{2}{*}{ Extract } & Total phenol & \multirow{2}{*}{$\frac{\text { Flavonoid }}{\text { (gRE/100gExtract) }}$} & \multirow{2}{*}{$\begin{array}{l}\text { Tannin } \\
\text { (gGAE/100Extract }\end{array}$} \\
\hline & & & (Ggae/100g Extract) & & \\
\hline 1 & & Pet ether & $8.67 \pm 0.12$ & $8.26 \pm 0.08$ & $3.15 \pm 0.17$ \\
\hline 2. & M.S. Leaves & Chloroform & $8.89 \pm 0.07$ & $11.75 \pm 1.22$ & $2.96 \pm 0.50$ \\
\hline 3 & & Acetone & $23.46 \pm 0.78$ & $17.43 \pm 0.86$ & $6.30 \pm 0.79$ \\
\hline 4 & & Methanol & $40.71 \pm 0.94$ & $20.61 \pm 0.28$ & $7.82 \pm 3.23$ \\
\hline 5 & & Water & $19.54 \pm 0.15$ & $15.03 \pm 0.72$ & $3.83 \pm 0.36$ \\
\hline
\end{tabular}

*Values are mean of replicate determination $(n=3) \pm$ standard deviation. GAE $(p<0.05$ where $a>b>c)$

Table 3: Minerals analysis of Meliosma simplicifolia

\begin{tabular}{lll}
\hline S. No. & Paramenters & Leaf \\
\hline 1 & Potassium & $50292 \mathrm{ppm}$ \\
2 & Magnesium & $5871.17 \mathrm{ppm}$ \\
3 & Sodium & $1006.03 \mathrm{ppm}$ \\
4 & Chromium & $2.32 \mathrm{ppm}$ \\
5 & Manganese & $34.56 \mathrm{ppm}$ \\
6 & Nickel & $8.04 \mathrm{ppm}$ \\
7 & Copper & $113.54 \mathrm{ppm}$ \\
8 & Zine & $20.26 \mathrm{ppm}$ \\
9 & Selenium & $28.62 \mathrm{ppm}$ \\
\hline
\end{tabular}

ppm: parts per million

to the medicinal activity of that plant. The comparison of the mass spectrums with the data base gave more than $90 \%$ match as well as confirmatory compound structure match. The GC-MS analysis of the methanol extract resulted many compound which have diverse use. Theses compound are having so mainly medicinal purpose as such as anti-inflammatory, antibacterial, antifungal, acute toxicity, and anticancer, skin conditioning properties have been identified (Fig. 2).

\section{Antibacterial activity}

The antibacterial activity of the $M$. simplicifolia methanol extract. The zone of inhibition was maximum at the concentration $(100 \mu \mathrm{g} / \mathrm{ml})$ of given sample the highest zone of inhibition was observed in staphylococcus pyogenes $(36 \pm 0.06 \mathrm{~mm})$ at concentration of $100 \mu \mathrm{g} / \mathrm{ml}$. Similarly, the lowest zone of inhibition was observed in Enterococcus aerogenes $(15 \pm 0.05 \mathrm{~mm})$ at concentration of 25 $\mu \mathrm{g} / \mathrm{ml}$. The results confirm that the given sample shows excellent antibacterial activity (Table 4 and Fig. 3). Antibacterial activity of $M$. simplicifolia leaf methanol extract.

\section{DISCUSSION}

The phytochemical test showed that a positive result for the primary metabolites such as proteins, carbohydrate, and amino acids are present in the appreciable amount in all the parts. Among the leaf is used to seem therapeutically important part which possesses a higher amount of secondary metabolites, such as phenolic compounds, flavonoids, tannins, saponins, steroid, and terpenoid. Quantitative studies of estimated phenol, flavonoid and tannin, as for the methanol extract of leaf showed the highest content of phenolic compounds $(40.71 \pm 0.94$ GAE mg/100). The methanolic extract of stem showed highest amount of tannin content $(7.82 \pm 3.23 \mathrm{GAE} \mathrm{mg} / 100)$. The flavonoid content is presented of methanol extract of $M$. simplicifolia stem revealed maximum amount of flavonoid content $(20.61 \pm 0.28 \mathrm{RE} / 100 \mathrm{~g})$. The stem of M. simplicifolia was collected, separated, and then the powdered material was extracted with various solvents using such as petroleum ether, chloroform, acetone, and methanol using maceration method. Extract yield percentage of methanol shows most recovery percentage (leaf-10.4\%) compared with other solvents. Antioxidant activities were concluded the estimation M. simplicifolia leaf for as followed the studies in stem the methanol extract showed the highest DPPH scavenging activity $(132.1 \mu \mathrm{g} / \mathrm{ml})$. In this present study, the analysis was carried out with dried stem sample of M. simplicifolia. From the ICP-MS, we can see clearly that each band represent characteristic absorption peaks of

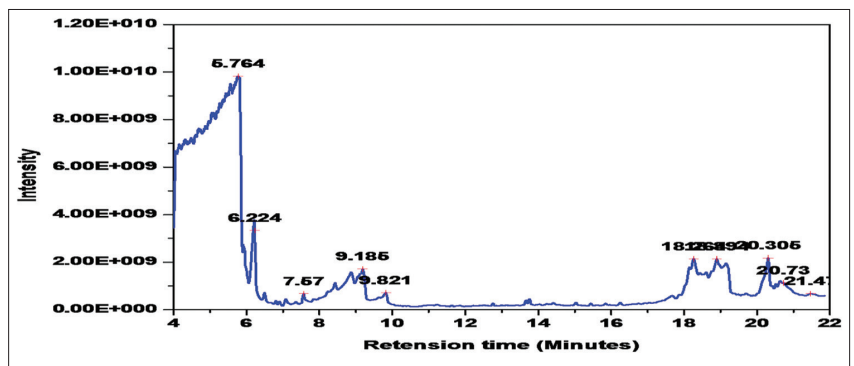

Fig. 2: GC-MS of the plant Meliosma simplicifolia leaf of methanol extract

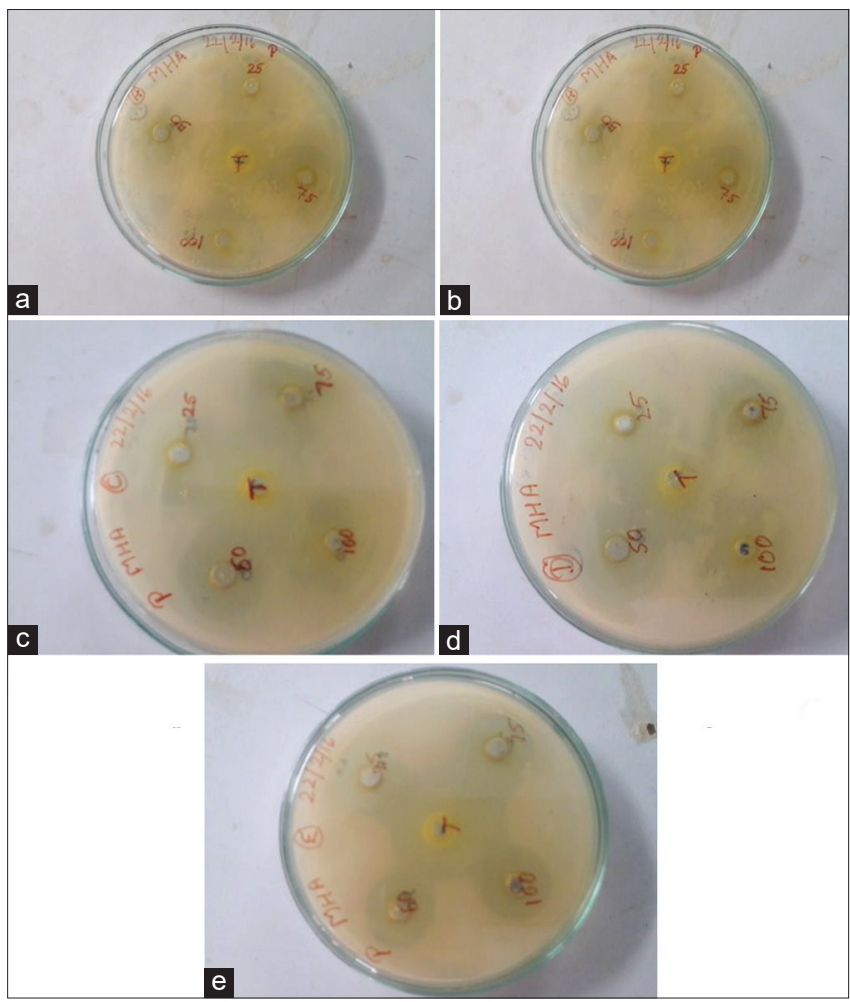

Fig. 3: Plates for Antibacterial activity of Meliosma simplicifolia leaf methanol extract. (a) Staphylococcus aureus,

(b) Staphylococcus pyogenes, (c) Klebsiella pneumonia,

(d) Pseudomonas aeruginosa, (e) Enterococcus aerogenes

functional groups present in the sample. Thus, the presence of phenolic in any plant sample indicates it as a potent source of therapeutic agents for different human disorders. GC-MS are a commonly used method for identifying the bioactive compounds, which is one of the most important analytical techniques used in quality control of herbal medicine. The present study identified several compounds, which were not describing din $M$. simplicifolia earlier. In the present study, M. simplicifolia extracts have great potential as antibacterial 
Table 4: Antibacterial activity of Meliosma simplicifolia leaf methanol extract

\begin{tabular}{llllc}
\hline Organisms & Control $(\mathbf{1 0 0} \mu \mathbf{g} / \mathbf{m l})$ & \multicolumn{3}{l}{ Zone of inhibition in diameter $(\mathbf{m m})$} \\
\cline { 2 - 4 } & & $\mathbf{2 5}(\boldsymbol{\mu g} / \mathbf{m l})$ & $\mathbf{5 0}(\boldsymbol{\mu g} / \mathbf{m l})$ & $\mathbf{7 5}(\boldsymbol{\mu g} / \mathbf{m l})$ \\
\hline Staphylococcus aureus & $38 \pm 0.5$ & $28 \pm 0.05$ & $30 \pm 1.03$ & $33 \pm 0.05$ \\
Staphylococcus pyogens & $35 \pm 0.5$ & $25 \pm 0.01$ & $27 \pm 0.03$ & $32 \pm 0.07$ \\
Klebsiella pneumonia & $36 \pm 0.4$ & $22 \pm 0.05$ & $25 \pm 0.05$ & $32 \pm 0.03$ \\
Pseudomonas aeruginosa & $34 \pm 0.1$ & $26 \pm 0.5$ & $25 \pm 0.03$ & $30 \pm 1.02$ \\
Enterococcus aerogenes & $25 \pm 1.03$ & $15 \pm 0.05$ & $17 \pm 0.04$ & $35 \pm 0.01$ \\
\hline
\end{tabular}

compounds against microorganisms. In addition to this, the results of the antioxidant profile can be used as pharmacological tool for the medicinal purposes of this plant.

\section{CONCLUSION}

The phytochemical extraction was done as per the protocol of leaf. The results confirmed the presence of phytochemicals such as phenols, flavonoids, and tannins in the higher in proposed plant. ICP-MS analysis of the leaf extract showed the presence minerals such as $\mathrm{Mg}, \mathrm{Fe}, \mathrm{Cu}$, $\mathrm{Na}$, and $\mathrm{Zn}$ in excess. Moreover, antioxidant studies were performed for the plant extracts. Various assays were used to screen these particular compounds and they were further confirmed by GC-MS the results showed that the stem extract has more antioxidant activity compared to leaf. The leaf extract of the plant was also tested for its anti- therapeutic potentials and results confirmed that it has potential activity. The study will also gear up the effort to protect, conserve, and cultivate such medicinal plants for the disease-free future of human.

\section{ACKNOWLEDGMENT}

The authors are grateful to Professor and Head, faculty, Department of Botany, Bharathiar, University, Coimbatore, Tamil Nadu, for providing necessary facilities during the study.

\section{AUTHORS CONTRIBUTIONS}

Pavithra designed the experiments performed in laboratory analysis, experiments, data analysis, and participated in the writing of the manuscript. Dr.T.Sekar helped in paper writing and correction. Authors discussed the results and commented on the manuscript.

\section{CONFLICT OF INTERESTS}

Declared none.

\section{REFERENCES}

1. Bahramikia S, Ardestani A, Yazdanparast R. Protective effects of four Iranian medicinal plants against free radical-mediated protein oxidation. Food Chem 2009; 115:37-42

2. Jadhav SJ, Nimbalkar SS, Kulkarni AD. Lipid oxidation in biological and food systems. In: Madhavi DL, Deshpande SS, Salunkhe DK, editors. Food Antioxidants. New York: Dekker Press; 1996. p. 5-63.

3. Singh AP. Promising phytochemicals from Indian medicinal plants. Ethnobot Leaflets 2005;1:18

4. Cook NC, Samman S. Flavonoids--chemistry, metabolism, cardioprotective effects, and dietary sources. J Nutr Biochem 1996;7:66-76.

5. Huang DJ, Chen HJ, Lin CD, Lin YH. Antioxidant and antiproliferative activities of water spinach (Ipomoea aquatica Forsk) constituents. Bot Bull Acad Sin 2005;406:99-106.

6. Pourmorad F, Hosseinimehr SJ, Shahabimajd N, Antioxidant activity, phenol and flavonoid contents of some selected Iranian medicinal plants. S Afr J Biotechnol 2006;5:1142-5.

7. Duh PD, Tu YY, Yen GC. Antioxidants activity of aqueous extract of harnjyur (Chrysanthemum morifolium Ramat). Lebensm Wiss Technol 1999;32:269-77.

8. Savithramma N, Rao ML, Rukmini K, Devi PS. Antimicrobial activity of silver nanoparticles synthesized by using medicinal plants. Int J Chemtech Res 2011;3:1394-402.

9. Kumar A, Bello B, Reichert H. Lineage-specific cell death in postembryonic brain development of Drosophila. Development 2009; $136: 3433-42$

10. Makkar HP. Quantification of Tannin in Tree and Shrub Foliage: A Laboratory Manual Dondrecht. The Netherlands: Kluwer Academic Publishers; 2003. p. 130.

11. Zhishen J, Mengcheng T, Jianming W. The determination of flavonoid contents in mulberry and their scavenging effects on superoxide radical. Food Chem 1999;64:555-9.

12. Blois MS. Antioxidant determinations by the use of a stable free radical. Nature 1958;181:1199-200.

13. Chan KW, Tan GH, Wong RC. ICP-MS method validation for the analysis of trace elements in illicit heroin. Anal Lett 2012;45:1122-32.

14. Perez-Eid C, Pauli M, Bazerque P. An antibiotic assay by agar-well diffusion method. Acta Biol Med Exp 1990;15:113-5.

15. Jeong SM, Kim SY, Kim DR, Nam KC, Ahn DU. Effect of heat treatment on the antioxidant activity of extracts from citrus peels. J Agric Food Chem 2004;52:3389-93.

16. Loo AY, Jain K, Darah I. Antioxidant activity of compounds isolated from the pyroligneous acid, Rhizophora apiculata. Food Chem 2008; 107:1151-60

17. Wildman RE. Classifying nutraceuticals. In: Wildman RE, editor. Handbook of Nutraceuticals and Functional Foods. Boco Raton, USA: CRC Press; 2001. p. 13-30. 